(b) Use of Red Cross Adult and Youth Volunteers in the Community

- in the health field,

- in the social welfare field,

- in the education field.

(c) Recruitment and Training of Adult and Youth Volunteers.

6. International Health Teams.

\title{
A RESOLUTION OF IMPORTANCE FOR THE RED CROSS
}

On 20 December 1968, the United Nations General Assembly Plenary Session unanimously adopted the resolution quoted below. In it the United Nations affirms principles proclaimed by the XXth International Conference of the Red Cross at Vienna in 1965. In addition, it associates the Red Cross in the work of promoting the better application and development of international humanitarian law.

During the discussions at New York the ICRC was represented, with observer status, by its Director, Mr. C. Pilloud, who was available for consultation by the General Secretariat and delegates. The draft resolution was submitted jointly by the delegations of Afghanistan, Denmark, Finland, India, Indonesia, Iraq, Jamaica, Jordan, Norway, Philippines, Sweden, Uganda, United Arab Republic, Yugoslavia and Zambia.

The General Assembly,

Recognizing the necessity of applying basic humanitarian principles in all armed conficts,

Taking note of resolution No. XXIII on "Human Rights in Armed Conflicts", adopted on 11 May 1968 by the International Conference on Human Rights, held at Teheran,

Affirming that the provisions of the resolution need to be effectively implemented as soon as possible, 


\section{IN THE Red Cross World}

1. Affirms resolution XXVIII of the 20th International Conference of the Red Cross in Vienna in 1965, which laid down inter alia the following principles for observance by all governmental and other authorities responsible for action in armed conflicts:

"- that the right of the parties to a conflict to adopt means of injuring the enemy is not unlimited;

" - that it is prohibited to launch attacks against the civilian populations as such;

" - that distinction must be made at all times between persons taking part in the hostilities and members of the civilian population to the effect that the latter be spared as much as possible;

2. Invites the Secretary-General, in consultation with the International Committee of the Red Cross and other appropriate international organizations, to study:

(a) steps which could be taken to secure the better application of existing humanitarian international conventions and rules in all armed conflicts, and

(b) the need for additional humanitarian international conventions or for other appropriate legal instruments to ensure the better protection of civilians, prisoners and combatants in all armed conflicts and the prohibition and limitation of the use of certain methods and means of warfare;

3. Requests the Secretary-General to take all other necessary steps to give effect to the provisions of the present resolution and to report to the General Assembly, at its twenty fourth session, on the steps taken by him;

4. Further requests Member States to extend all possible assistance to the Secretary-General in the preparation of the study requested in paragraph 2 above;

5. Calls on all States which have not yet done so to become parties to the Hague Conventions of 1899 and 1907, the Geneva Protocol of 1925, and the Geneva Conventions of 1949. 